\title{
13
}

\section{Learning at work}

\author{
K. Thoresen \\ Norwegian Computing Center \\ Box 114, Blindern, 0314 Oslo, Norway \\ Phone: 47-22 852500 Fax: 47-22 697660 \\ Email: Kari.Thoresen@nr.no
}

\begin{abstract}
Organizational implementation of IT systems requires distribution, sharing and pooling of knowledge of how the system can be used in daily practice. This paper analyzes processes of 'learning at work' as they emerge in groups of workers using IT for management and monitoring of the long lines and trunk networks in a telecommunications company. It is shown how resources for learning are socially structured, and how most of the learning takes place as an integrated aspect of the primary work. Thus, learning at work is also learning through work. The concept of 'organizational learning' is discussed relative to the study, and it is argued that the cognitive perspective on organizational learning tends to obliterate some of the important aspects of learning at work.
\end{abstract}

\section{Keywords}

Communities-of-practice, organizational learning, implementation.

\section{PoINT OF DEPARTURE}

How do organizations learn to use their IT systems as a means to carry out their primary work ? It may seem odd to talk about organizations using IT systems, since it is always individuals who use systems. However, there are aspects of adoption of IT that cannot be ascribed to individuals alone. One condition for successful adoption is distributed and shared knowledge regarding use among the networkers. Monopolized knowledge, residing in a computer department or in local gurus mainly, is likely to increase vulnerability and reduce the sustainability of the learning process. A previous study (Bermann and 
Thoresen, 1992) showed how the same IT system used in two different hotels contributed to markedly different effects due to the different emphasis on distributed learning.

If we look at adoption and appropriation of IT systems as a variety of organizational change, broad integration is one of the building blocks that facilitates change, as illustrated by Kanter (1988):

'If innovations are isolated, in segmentalist fashion, and not allowed to touch other parts of the organization's structure and culture, then it is likely that the innovation will never take hold, fade into disuse, or produce a lower level of benefits than it potentially could (p.299)'

'Learning at work' refers to these processes of distributing and sharing knowledge in the organization as a part of daily practice. These are long-term processes, constituted by a combination of planned and accidental circumstances. It is necessary to distinguish between 'learning' and 'training'. Planned efforts like e.g. training programs or courses, are elements in learning at work, but their impact is variable.

The questions underlying the present study are as follows:

- How does the distribution and sharing of knowledge* regarding use of IT systems take place in organizations?

- What are the resources used in the above processes?

- What are the elements - technical and organizational - that facilitate and hinder learning at work?

To study the questions outlined above, two IT systems in the Norwegian company Telenor have been selected. This paper reports on one of them - NetSys - a system for the management of the long lines and trunk networks in Telenor. NetSys is used by workers from different job categories, whose primary work is related to the management, monitoring and maintenance of the network.

\section{Focus and time-span}

The learning perspective underlying this paper differs in some respects from more familiar perspectives, such as diffusion or decision. Scenarios from a decision perspective often adopt a top-down approach, as seen in much of the management literature. As noted by Wardell (1992):

This scenario, ....., can be broadly characterized as a top-down approach. Overall, the approach explicitly portrays shop-floor activity and the organization of the workplace as being shaped almost entirely by the efforts of managers who respond to a problematic environment. (p.144)

In this paper, the focus is on the daily practice of the technical and clerical staff and their supervisors.

\footnotetext{
* The author is aware of the problems inherent in using 'knowledge' in singular. It may give the impression of a unified body of knowledge. See section on 'Expert users' for a more detailed explanation.
} 
Following Herbig and Kramer (1993), diffusion is the process of adoption by potential users of a technology or innovation. Adoption may be conceived as a two-stage process where the initiation consists of all of the information-gathering, conceptualizing, and planning for the adoption of an innovation, leading up to the decision to adopt, and the implementation, all of the events, actions and decisions involved in putting an innovation to use (Van de Ven and Rogers, 1988). The implementation stage can further be said to consist of all events and actions pertaining to modification in both an innovation and an organization, initial utilization and continued use of the innovation when it becomes a routine feature of the organization (Damanpour, 1991).

In the present study, decision to adopt is not a topic, the networkers must cope with what they have. However, coping means both adapting to the existing technical and organizational frameworks, and at the same time, actively shaping the frameworks according to the networkers' needs. The emphasis is therefore on the interplay between the topdown and bottom-up processes of integrating NetSys in the organization. This is an aspect of the implementation stage outlined above.

The time-span concerns the period from initial installation of the system in 1985 until now with an emphasis on the period of 1993-1995, i.e. fairly late in the implementation process.

\section{Why these topics are interesting}

From a practitioner's view, learning at work is necessary to obtain substantial results from investments in IT. Marketing 'hype' implicitly or explicitly claims that results come with the equipment; unfortunately this is contradicted by the experiences of many organizations (see e.g. Keen, Bronsema and Zuboff, 1982, Rowe, 1985, Franke, 1987, Zuboff, 1988, Duimering et al., 1993). Today it is common knowledge that learning and organizational changes are needed in order to reap benefits.

The trend towards integrating systems across organizational boundaries, adds a new dimension of heterogeneity. There is widespread recognition of the challenges inherent in this trend, for instance regarding networking (Clement et al., 1994, Wagner, 1994). Another example is the "work-flow thinking" of business process reengineering (see e.g. Hammer, 1990, Jones, 1994, Iden 1995). How does the increased heterogeneity of user groups influence the learning processes ? Will a wider spectrum of training programs be required? Furthermore, how can heterogeneous groups learn from each other?

\section{ORGANIZATIONAL LEARNING - SOME CONSIDERATIONS}

From a theoretical perspective, issues of learning in organizations are often categorized as 'organizational learning'. Organizational learning is one of the fashionable terms in current literature, in particular management literature (see e.g. special editions of Organization Science, 1991, Organization Studies, 1993, and Organizational Dynamics, 1993). It is also a slippery term in the sense that it takes on different, and sometimes unclear meanings depending on the author, the discipline and the area of study. 
Dodgson (1993) remarks that 'conceptions of organizational learning are ubiquitous.' He claims that one of the reasons for the popularity of the concept is its broad analytical value. This may be seen in the diversity of use in different disciplines - economic history, industrial economy, management, organization theory, psychology etc. He also views 'organizational learning' as an integrative concept. It can be used to unify various levels of analysis: individual, group, corporate. However, Huber (1991) notes the lack of cumulative work and lack of integration of work from different research groups, which indicates that the broad analytical value may be more of a potential than a reality.

\subsection{Grounding organizational learning}

The literature on organizational learning is rich and varied (see e.g. Huber, 1991, Orr, 1992, Dodgson, 1993, Cook and Yanow, 1993, ). There are, however, complementary strands in the literature that differ markedly in their view of what organizational learning is. These strands see organizations as cognitive entities, and as communities-of-practice, respectively ${ }^{1}$.

\section{Organizations as cognitive entities}

This perspective sees organizational learning as modelled after individual learning, in two different ways:

- Individuals learn in organizational contexts. Change comes about because key individuals have the power and influence to change organizational behaviour (see e.g. March and Olsen, 1979, Simon, 1991).

- Organizations are seen, metaphorically, as humans -- with perceptive organs, brains, memories etc. (see e.g. Hedberg, 1981, and Weick, 1991).

Several aspects that were central to the present study were difficult to locate in the literature. While the study of networkers emphasized the centrality of work practice relative to organizational learning, work practice was hardly visible in the literature. Likewise, the everyday dynamics that characterizes organizations, is mostly invisible in the literature. The literature gives an impression of distance to the learners' daily work -- the remote view (see e.g. Dorroh et al., 1994, Levitt and March, 1988). Some problems related to the remote view are outlined below. It is suggested that 'learning at work' is a more appropriate concept for the kind of organizational learning illustrated in this study.

\section{The remote view}

Sachs (1994) distinguishes between 'activity'- (or 'work'-) oriented thinking, and 'organization'-oriented thinking for the purpose of representing work for systems design.

From an organizational perspective, work is conceptualized as a set of clearly defined tasks and operations, described in methods and procedures which fulfill a set of business functions. This view of work differs from an activity-oriented approach which suggests that the range of activities, communication practices, relationships and coordination it takes to

\footnotetext{
* The line of argument in this section is based on Cook and Yanow, 1993.
} 
accomplish business functions, is complex and continually mediated by workers and managers alike. (Sachs, 1994, p. 36)

This is in accordance with a number of studies of work practice (Wynn, 1979, Strauss et al, 1985, Suchman, 1983, 1987, Lave and Wenger, 1991, Gerson and Star, 1986, Orr, $1991,1992)$ that show how efficient work is characterized by the workers' ability to discover, define and solve problems when they arise, rather than by their skill in following procedures. Task descriptions and procedures may at best function as resources for action (Suchman, 1987). At worst they may be so remote from the practical problems the procedures were intended to solve that they are dismissed by the potential users (Orr, 1991). Most of us know this from our own experience, for instance, when trying to follow instructions for which actions to take when the copier breaks down. From the remote view, contingencies, shortcuts and local adaptation become less visible. The remote view (see e.g. Dorroh et al., 1994, Levitt and March, 1988) obliterates the concrete actions taking place, making it difficult to understand how the reported results came about.

Blomberg (1993) points out:

Learning about work from a distance tends to result in descriptions of the work that are overly idealized and that fail to reveal unremarkable, yet consequential, aspects of the work (p.11).

One such unremarkable, yet consequential aspect of the work, is the learning that takes place -- learning interwoven with daily practice. Orr (1992) notes the peculiar fact that in the literature on organizational learning, learning is seen as problematic, while ethnographic studies all seem to find that people learn easily, continuously and virtually automatically.

Although it would be an exaggeration to say that this holds for the networkers as well, there are aspects of their learning processes that resonate with the above view (see also section on Resources for learning).

\section{Everyday dynamics}

Organizations are fluid entities, in the sense that they are continually changing. They are engaged in long-term change processes as well as short-term changes pervading daily life at work. These everyday dynamics are also visible in the present study and are further discussed in chapter 9 on embedded groups. However, this fluidity make the concept of 'organization' problematic.

Orr (1992) discusses the elusiveness of 'organization' as an entity. Based on studies of service technicians in a large corporation which manufactures photocopiers, he claims that the term 'organization' does not capture the multiple realities of 'organization' as experienced by its members. For one thing, membership is fluid. For the service technicians: ....even field service as an organization is not a coherent entity either. There is 'this district' as opposed to 'that district', and then there is 'this team' as opposed to other teams or the district itself. Within teams there are workgroups, and within workgroups there are 'Customer Service Teams.' These are composed of two or three individual technicians. Thus there is an array of organizations at play in the service organization, with substantial- 
ly or wholly overlapping memberships, and yet there is a clear choosing of which membership is appropriate at a given time. (Orr, 1992, p.3-4)

The basic question raised here concerns the problems inherent in delimiting the unit of analysis when it is dynamic. It is often difficult to glean from the literature what kind of entity is referred to as an 'organization'. A company ? A team ? A group of managers ? A department ? Although there is a high degree of consensus that the fundamental learning entity is an individual (Fiol and Lyles, 1985), the leap from the individual to the organization, at whatever level, remains vague.

\section{Organizations as communities-of-practice}

The focus on organizations as communities-of-practice represents a cultural perspective, rather than an organizational or managerial. Examples are found in e.g. Lave and Wenger (1991), Brown and Duguid (1991), Orr (1992) and Cook and Yanow (1993).

A characteristic of organizations as communities-of-practice is their ability to carry out collective activities. The ability to act is attributed to the group, not only the individual or the sum of individuals. A symphony can only be played by the orchestra, not by any individual musician, not even by the sum of individual musicians. Rehearsals and performances are dependent on mutual interactions in real-time between the conductor and the orchestra members, and among the orchestra members: listening, correcting, enhancing, changing the elements of the musical performance as it unfolds. Thus it makes sense to say that a group acts, and that the individual musicians can act on their abilities only in the context of an orchestra. Focus shifts from individuals in organizational contexts, to groups of individuals in a web of commitments regarding a production process.

In Lake City, the whole group of networkers are involved in order to keep the network in optimal shape. The group's actions encompass both things the individual alone can do, but also actions involving cooperation and interdependence. The various subgroups depend on each other to carry out the orders, and each subgroup in turn can only do this by cooperating among themselves and with other work groups.

Another characteristic of organizations as communities-of-practice is that the ability to act is based on knowledge that resides in the organization as a whole. An individual networker may know how to carry out her own activities, but she depends on other networkers' knowledge. The person resonsible for signing off completed orders knows about the technical details of sign-offs. However, that is insufficient in order to provide the collective product. She depends on networkers all over the region to do their part and sign-off locally, and she can't just sit and wait for it to happen. She actively checks where there are missing sign-offs, she calls the relevant persons to find out why they are late, and breathes down their neck if necessary. It is not her knowledge only, neither is it the accumulated knowledge of a number of individuals -- it is collective knowledge that comes into being through interactions regarding work.

The third characteristic points to a phenomenon which is almost absent in the cognitive perspective: Organizational learning is preservative as well as innovative. The preservative variety of learning concerns not losing professional identity, to 
continue to be able to do what they are good at. Cook and Yanow (1993) point out how a group of flutemakers of high reputation strives to maintain their professional identity as makers of 'the finest flutes in the world' while accommodating an innovation in the form of a new scale. The same concern runs like a red thread through my material: the obligation expressed by the networkers to provide high quality network services despite the turbulence of organizational and technological changes. In some cases, what is called 'resistance to change' in the literature, may in fact be preservation.

Organizational learning is seen as the acquiring of knowledge that enables the group to carry out their collective activities. By taking into account the actual work that is carried out, the relationship between knowledge and work becomes visible. Chapter 9 and 10 discusses some of the resources and strategies employed by the networkers for this purpose.

\section{THE CONCEPT OF LEARNING}

The concept of learning underlying this paper emphasizes the relationship between knowledge and action. I have gradually come to see learning as a potential change in the repertoire of actions, based on knowledge. Some points in this specification need clarifying.

First, the change may be potential, not necessarily manifest. The networkers may know how to carry out specific tasks, e.g. from courses or manuals, but do not try it out in their daily work, for instance due to division of work. This correspond to the concept of 'role-constrained' learning (March and Olsen, 1976).

Second, learning is not limited to improvement -- change may imply an increase or a reduction of the repertoire of actions. Work skills once learned may diminish if not practiced regularly. A variety of help-seeking approaches may, for instance, be replaced with one standardized approach. Hedberg (1981) used the concept of 'unlearning' to denote a process through which learners discard knowledge.

Third, there is not necessarily a fixed sequence between knowledge and action. Knowledge may precede action, but action may also precede knowledge. The networkers may find their way through the system by trial-and-error approaches, and use such approaches to develop a more coherent understanding of the system. It is the 'maybe-it-will-work-if-I-push-that-button' syndrome that most of us are familiar with.

Hanks (1991) expresses a similar view on learning:

The individual learner is not gaining a discrete body of abstract knowledge which (s)he will then transport and reapply in later contexts. Instead, (s)he acquires the skill to perform by actually engaging in the process, under the attenuated conditions of legitimate peripheral participation (author's italics) (p.14).

Thus, a condition for learning at work is the access to close cooperation and communication with coworkers regarding work. The paper focus on the processes through which this occur. 


\section{TELENOR AND ITS BUSINESS CONTEXT*}

Telenor is the former 'Televerket', which until recently was the only national tele-operator in Norway. For more than a century it has been one of Norway's largest public institutions, occupying a monopoly position in the telecommunications field until a deregulation opened up the Norwegian market in the late 1980's. The European Union has launched January 1, 1998 as the D-Day for free telecommunication markets in Europe, and international alliances are continually being forged.

One of the target groups for new operators in Norway is that of large companies, which are also a major source of income for Telenor. This makes Telenor vulnerable to competition regarding the large customers. In most of the private customers market, and parts of the company market, Telenor may keep its dominating position, due to its history and its size. It is still by far the largest operator in the Norwegian market. Pressure is expected from larger operators with higher productivity and lower costs, and from specialists of customized value-added services.

Two of the Telenor's organizational changes -- changes originating as responses to the environment, are essential to this study: from public monopoly to a (semi)-private company; and from a functional bureaucracy to a divisionalized structure. A cultural transformation -- from a corporate culture based on administration of public services to customer-orientation -- is part of the parcel. The transition from a public monopoly to a company, although wholly owned by the state, took place formally January 1, 1995. Preceding the formal event, a series of reorganizations have taken place, accompanied by downsizing. The number of employees in the period 1965-1992 reached a peak of more than 22.000 in 1987 before declining to slightly more than 18.000 in 1991 . Top management claims that further reduction is needed, in order to meet the competition.

In 1992-93 the divisionalization took place, including a geographical change where 27 tele-areas were allocated to 7 regions (Figure1). At the end of 1994 the divisions were reorganized into separate units. During the later years, a number of subsidiary business units have been established, owned directly or indirectly by Telenor.

At the time of the field work, the main divisions in the mother company were the private market division, the company market division and the network division. Of a total turnover of roughly 2 billion NOK in 1994, the private market division counted for $34 \%$, the company market division for $26 \%$ and the network division for $3 \%$. However, this figure represents only the external turnover for the network division. In 1995, more than $90 \%$ of expected turnover for the network division will come from internal invoicing.

As seen from Figure 1, all regions encompass these divisions, giving a matrix-based structure. TRP (Telenor Resource Pool) is intended to develop new business areas and offer further education for surplus personnel. There are central and regional staff functions for IT, research, education, material administration, property management etc.

\footnotetext{
* The section is based upon information from 'Åpen linje' -- the Telenor internal newspaper, in particular the articles by S.Karlsen.
} 


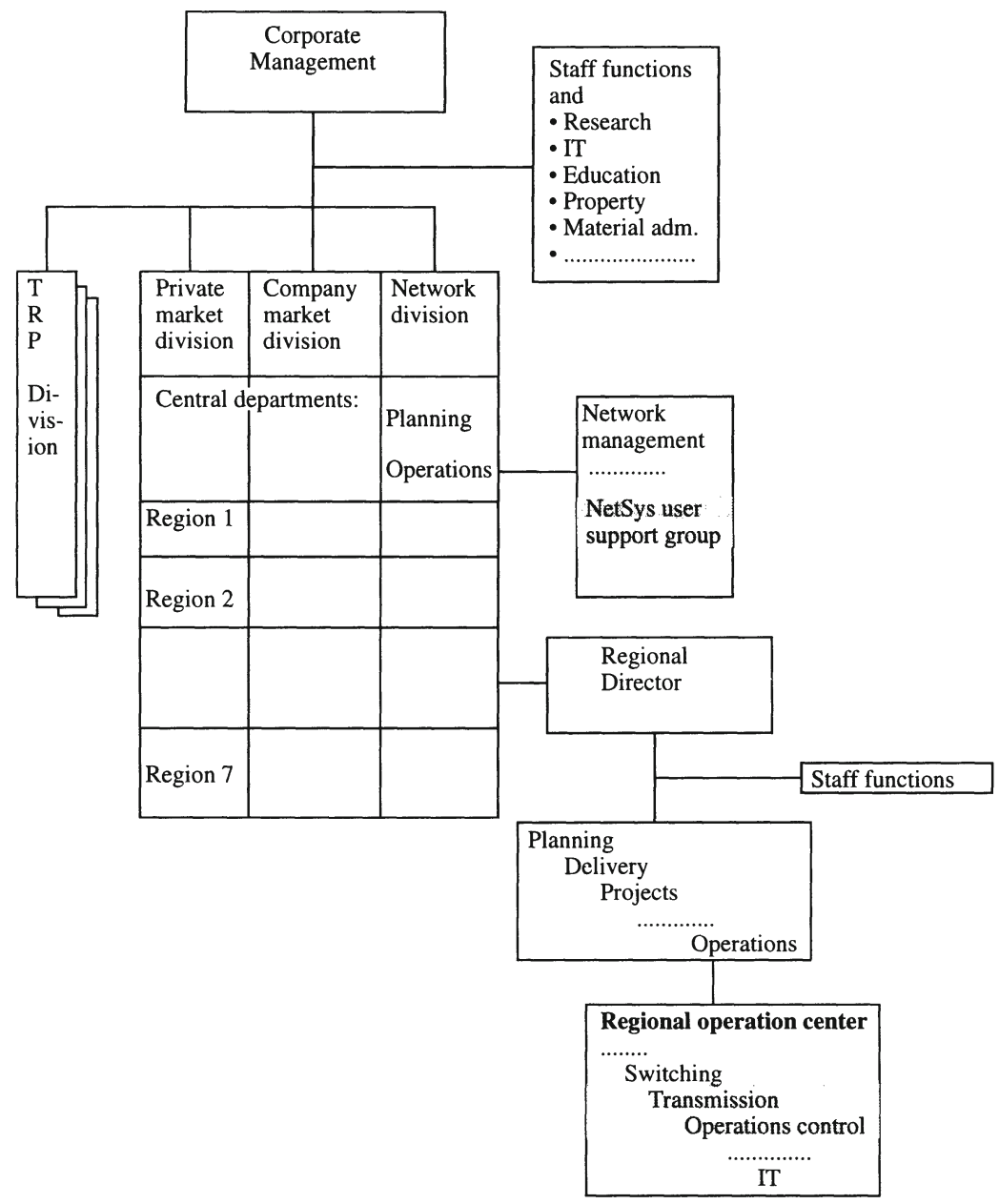

Figure 1. Simplified organizational chart of Telenor showing the relevant organizational units (shaded) and their location in the overall organizational framework. On the regional level: transmission and operations control (which includes both network allocators and operations control personnel), and on the central level: network administration, which encompass the user-support group. NOTE: This reflects the organization at the time of the field work. 
The study takes place in the network division during the turbulent times from 19931995. It is important to understand the impact of the turbulence in shaping the intervening conditions for the results reported here. Regarding the practical work, new routitines, power distribution, reporting channels, etc. were re-established. Some positions were filled with substitutes who sometimes did not know for how long they were to stay, or only reluctantly took on the jobs. The atmosphere of upheaval and unpredictability felt by the employees during this period, regarding for instance employment security, work load, job changes and rights to participate in decision processes at all levels, was marked. The change was felt all the more strongly due to Telenor's long history of stability, also regarding industrial relations.

\section{Methodology}

The material for this study was collected during field work in Telenor during the fall of 1993 and January-March 1995. The empirical material includes interviews with and observations of 11 persons - four women and seven men- working with different types of network management ('the networkers') in one of the regions. The networkers included operation control personnel, network allocators and transmission technicians. Nine of these work in the regional operation center in Lake City and two in a decentralized unit of the operation center. There are other groups that use NetSys in Lake City, for instance planners, but these are not included in the study so far. The empirical material further includes four persons - two women and two men - from the centrally located user-support group for NetSys, the IT system in question. Both the networkers and the user-support group belongs to the network division.

The interview framework was inspired by socio-technical analysis. Experience from previous projects (Pape and Thoresen, 1987, 1990) convinced us that socio-technical analysis was well suited for analyzing formal and informal work-related interdependencies, which are essential for learning purposes. The limitations of the method are partly due to the lack of operationalization of the social analysis, in particular regarding reproduction and development of knowledge. Therefore the interview framework emphasized the informal social networks involved in defining and solving work-related problems, including NetSys.

Other information sources are interviews and discussions with one of NetSys' chief designers, participation in a one-week regular NetSys training course, participation in a Users' Forum meeting and document studies.

Grounded theory (see e.g. Glaser and Strauss, 1967, Glaser, 1978) has been used for data analysis. The emphasis is on developing concepts and integrating these concepts for the purpose of theory building. The study does not support conclusions regarding the relative importance of the phenomena observed, due to the small number of networkers and the fact that the field site is limited to one region. Comparisons between several regions are required in order to answer such questions.

The study intends to contribute to substantive theory. In grounded theory, substantive theory is developed for a specific empirical area, in contrast to formal theory which is 
developed for a conceptual area. However, the material is still in the early stages of analysis, and grounded theory will be used for reframing topics for further field work and data analysis.

\section{NETSYS - A BRIEF OVERVIEW}

NetSys is a system for administration and management of the long lines and trunk networks in Norway. The first version in general use was introduced in 1985, and NetSys is now used in all Telenor areas, with approximately 1200 active users. Despite resistance from some groups, NetSys has displayed a remarkable stamina. It has been able to incorporate new telecommunication technologies unheard of at the time of its conception. The centralized database has grown steadily and now represents an unquestionable asset to Telenor. Additional applications built on the same design rationale have contributed to the organizational integration of NetSys.

The description below concentrates on some of the features that are most relevant for use. A more detailed description is given in Thoresen (1995).

\section{Configuration}

The configuration contains three large mainframes with a centralized database. The users have terminals, PC's and printers connected to the central mainframes. The terminals may either be old, dedicated IBM terminals, or newer X-terminals, which run an emulated 3270 version presented on the X-terminal. Most terminals are located in the respective offices of the different groups. This means that few transmission technicians have access to terminals while they are in the field, the terminals are used when the technicians return from field work.

At the time of the fieldwork, the PC's were mainly used for graphical presentations, together with a graphical plotter, but Lake City had not started to use the graphical module. At present, the 3270-terminals are replaced with PC's.

\section{Modules}

The main module in NetSys is the database, with information about the resources and connections in the long lines and trunk network. The database is used by all networkers. Before NetSys was implemented, Telenor had central and local archives which were updated when new circuits and nodes were installed, disconnected, allocated or expanded. With NetSys, the archives were converted into a centralized database covering the country as a whole.

There are a number of additional modules, and one is important in this paper: OrdSys an electronic mail system used for distributing orders concerning work to be carried out on the network by the transmission technicians. Before OrdSys, orders were printed out locally in a variety of text-based formats. After OrdSys, the orders can only be issued through the system, thus forcing the transmission technicians to use NetSys more. This implied a major step towards integration of NetSys in the organization. 


\section{Design rationale}

The NetSys database is designed as a model of the physical network* Conceptual data modelling was used as inspiration for the designers. These foundations later turned out to be inadequate. Today, the designers do not view the data definitions as models in a strict sense, but as syntactical definitions.

The design idea behind the physical network model is that the model should be common for various network technologies and independent of organization. Technological independence would facilitate the incorporation of new network technologies without costly redesign and programming. Unlike systems based on work functions, NetSys would be easily adaptable to various work tasks and contexts. Although the designers realized that in reality this is not fully achievable, their ambition has nevertheless been to develop something close to a context-free model of the physical network. Not only are there no attempts to capture work procedures, they are deliberately deleted as far as possible in the design process. Users are free to move around in the network model according to their own needs, in a modeless dialogue.

\section{Content and functionality}

At the time of data collection, NetSys featured 87 different screens, a number of batch system reports and graphic modules. The NetSys database contained close to 8000 nodes, 23.000 distances between nodes and 300.000 circuits.

The contents and layout of screens 'mirrors' the network model. The relevant attributes of a node, or a circuit, or a group etc. are displayed in a table-like format (for more detailed illustrations, see Thoresen, 1995). Commands and screens are text-based, and the system provides simultaneous dialogues in a Windows-like format. NetSys can be used with a flexible and complicated set of access permissions defining graded 'read' and 'write' access, assigned to work groups or persons with different work responsibilities.

\section{NETSYS AND THE USER GROUPS}

The newly established regional operation center in Lake City is one of 7 regional operation centers. The center is responsible for the optimal functioning of the network in their own region. They use several computer systems for this task, one of them is NetSys.

The operation control (OC) personnel monitor the network. In Lake City they are 6-8 persons, spending most of their work day in the operation control room (the OC room). The heart of the room is the OC desk with several alarm systems up and running. The OC personnel take turns at the desk, where alarms appear on the screen. Information about malfunctions also come in by fax, by phone or by other personnel shouting across the room. Operating the OC desk can be a stressful task, and the turn-taking was initiated as a response to the stress. The OC room also holds personnel from other work groups, among them fault recording personnel. Both private and company customers call to re-

\footnotetext{
* Information on design rationale is due to A.Meisingset. For papers discussing similar ideas, see Meisingset (1993).
} 
port malfunctions of all kinds. With the new divisions, fault recording personnel belongs to the private market or the company market division, not the network division.

When action is needed, the OC personnel forward alarm messages by phone or fax to other persons in the areas of the region where the malfunction is supposed to be. Later they follow up how things are going. They are responsible for warning the customers that will be affected when parts of the network go down. Since Lake City is the regional center, they must approve or reject requests from other Telenor areas in the region to disconnect parts of the network. Such decisions may be part of a planned operation, like digitalization, or part of emergency situations - to get the network up and running after failures.

The OC personnel use NetSys with read access only: to look up routings when customers complain, and to find out what parts of the network will be affected if circuits are cut in a particular area. They print out lists of which customers must be warned, who should be offered replacement phones etc. They use the system once or twice a day, between 15-30 minutes in all. When there is no network trouble, they may not use it for weeks.

The network allocators are the expert NetSys users. In Lake City, two persons have this job. Their job is to provide optimal use of the resources of the transmission network in their region: routing, technologies, reserves etc. The network allocators are located in a separate room in the $\mathrm{OC}$ room, in close contact with the OC personnel.

Through OrdSys the network allocators get input from regional and central planning departments regarding what installations are to be carried out in their region. However, the orders they get from planning may be seen as rough 'skeletons'. They are not always complete, and they may not always be correct. Since the network is continually under development, it is difficult for planners to be updated as to the status of the physical network. The planners may for instance indicate which exchange should be used, but don't always know whether that exchange is prepared or not. A part of the network allocators' job is to forward the orders, in revised versions, through OrdSys to the transmission technicians. The revised orders describe how and where the physical work on the network is to be carried out. They plan in detail what the planners have done in the large.

The other part of the network allocators' job concerns the NetSys database. They are responsible for updating the database and for data quality in their region. The network allocators use NetSys more or less the whole day, 4-6 hours at a minimum. Since they are expert users they are frequently interrupted, by local OC personnel who need their help, or by other NetSys users from across the region.

The transmission technicians make up the third group that use NetSys. They are the people who carry out the practical work on the long lines and trunk networks. A group of 10 persons in Lake City install, test and repair transmission equipment.

They get their orders through OrdSys printed out in the morning, travel to places where they carry out their work, return and do paper work and sign-offs on orders, and prepare for the new orders. They have a technical assistant, a woman who more or less runs the place when the technicians are out in the field. She is also the main NetSys user for the technicians. As a group, the transmission technicians use NetSys with both read 
and write access, though they are only allowed to perform one 'write' function: entering data for sign-offs. Most of them use NetSys at least 2-3 times a week, but for short periods of 5-15 minutes only.

Some transmission technicians dislike NetSys and have invented ways of working around the system. The sign-offs are delegated to the technical assistant, and the technicians may ask her for instance to look up a preview of the distance they will work on the next day. Sometimes they call her when they are out in the field. Some make it a policy to use NetSys as little as possible.

\section{RELATIONSHIP BETWEEN WORK AND LEARNING}

What are the elements that facilitate or hinder learning at work ? To answer the question, it must be kept in mind that learning NetSys is an aspect of learning and doing the primary work ${ }^{*}$. It is not a separate process, except on special occasions like e.g. formal courses or demonstrations of new functions. Thus, learning at work is situated, in the sense that it is:

tied in essential ways not to individual predispositions or conventional rules but to local interactions contingent on the actor's particular circumstances. A consequence of action's situated nature is that communication must incorporate both a sensitivity to local circumstances and resources for the remedy of troubles in understanding that inevitably arise (Suchman, 1987, p.28)

At first, it was puzzling that NetSys was seldom a topic when the networkers were talking among themselves at lunch, in meetings or in the coffee room. It emerged as a topic, however, embedded in their work tasks. The 'curriculum' is shaped by the demands of the primary work. The fact that Telenor has an obligation to inform certain customers when they are affected by network malfunctions is an opportunity for the networkers to learn to use NetSys to retrieve lists of these customers. A request to cut an optic fibre cable from a networker in a nearby valley may prompt the networkers in Lake City to learn to retrieve the relevant NetSys data to assess the feasibility of the request.

The close relationship to primary work is also reflected in the degree of familiarity with the system. For the Lake City networkers, use of NetSys is just one activity in a larger set of activities aimed at keeping the region's network in optimal shape. For the central usersupport group, use of NetSys is a means by which to provide the networkers with advanced knowledge of NetSys use, which occupies most of user-support's day. These differences in primary work manifest themselves in the frequency of use of different screens. While the networkers have a high usage score for 9 of 87 screens, the usersupport group scores high for 21 screens. Their primary work requires them to answer all sorts of questions about all screens. Most of the networkers do not need to know about that many screens, since their daily practice concentrates upon the use of some screens only. On the other hand, the networkers know a lot more about the network in

\footnotetext{
* 'Primary work' are the tasks in which computer use is embedded (see Gasser, 1986). The networkers' primary work is to keep the network in optimal shape and utilize its resources optimally.
} 
their region than the user-support personnel; who do not issue orders nor change the regional databases.

The concept of legitimate peripheral participation (Lave and Wenger, 1991) illustrates a similar view on learning as a situated activity:

Learning viewed as situated activity has as its central defining characteristic a process that we call legitimate peripheral participation (authors italics). By this we mean to draw attention to the point that learners inevitably participate in communities of practitioners and that the mastery of knowledge and skill requires newcomers to move toward full participation in the sociocultural practices of a community (p.29).

Legitimate peripheral participation is thus a precondition for learning, a precondition that emphasizes identity and membership of communities-of-practice.

The following sections will discuss some of the elements that contribute to participation in the networkers' communities-of-practice. Focus is on what might be called 'textural' aspects of the work organization. Textural aspects, as different from the structural aspects, refer to the fine-grained, interlocking and dynamic relationships among the networkers during daily practice*. These relationships cannot be seen from an organizational chart, texture emerges from studies of practice as it unfolds during daily work. Analyzing texture is one approach for obtaining the close view discussed previously.

\section{NETWORKS IN FLUX}

Since NetSys is appropriated as an integrated part of primary work, it becomes vital to understand those aspects of the primary work central to learning at work. Two phenomena emerge from the empirical data as particularly relevant, both related to the informal organization necessary to coordinate and carry out the work. Below, concepts for those two phenomena, links and embedded groups, are outlined. The intention is to provide tools for understanding the character of the informal organizational networks, and how parts of the social texture are shaped.

\subsection{Links}

A link refers to the relation between two persons carrying out different types of work. Links are important because they form the basis for cooperation. They pave the way for embedded groups, and facilitate the emergence of informal networks for many kinds of problem-solving. It is also characteristic that links have a kind of after-life: they often persist although the work-oriented relationship that brought them into being no longer exists. Thus links are a part of the socially structured resources used by the networkers in their daily practice.

Links may be due to direct relations, when the types of work are temporally next to one another in a sequence of work activities. The transmission technician may for

\footnotetext{
* The texture metaphor is also found in weaving, where texture denotes the surface created by the multiple combinations of warp and weft, and in geology, where texture denotes the geometric aspects of, and the mutual relations among the component particles or crystals of a rock, as seen in the microscope.
} 
instance not install the equipment themselves, but instead put it into operation when others have installed it. There may also be indirect links, where the types of work are further apart in a time sequence. When someone orders equipment, a person retrieves that equipment from the store, though not necessarily the person who initially received the order.

Links may exist or not. When they exist, they may have different states. They may be active, in the sense that some link is well established and can be trusted. They may be dormant, e.g. a link which was previously active may become active again. Links may be dead, for instance when someone quits. A link may have a location within or across one's unit and take on different forms, like delegation or assistance. Links are seldom bounded by formal authority structures and boundaries.

Active links are necessary prerequisites for learning. Links provide insight into larger parts of network management, by contacts with people with different knowledge and work tasks than one's own.

\subsection{Embedded groups}

The physical network is fluid in the sense that it is continually changing: malfunctions are repaired, areas are digitalized, new equipment and circuits are installed etc. This fluidity is to some extent reflected in the informal organizational networks, which continually reshape themselves to suit the requirements of the physical network. The reshaping occurs according to type of work to be performed, the urgency with which the work must be performed, and the scope of the work.

This dynamic reshaping gives rise to embedded groups, established for the purpose, but not visible in any chart nor visible from organizational positions far from the embedded groups themselves. They are groups in the sense that they cohere for some work-related purpose, although stability and membership may vary. They usually know each other and communicate freely.

Embedded groups are in many ways similar to communities-of-practice (Lave and Wenger, 1991, Brown and Duguid, 1991):

In using the term community, we do not imply some primordial culture-sharing entity. We assume that members have different interests, make diverse contributions to activity and hold varied viewpoints. In our view, participation at multiple levels is entailed in membership in a community of practice (authors' italics). Nor does the term community imply necessarily co-presence, a well-defined, identifiable group, or socially visible boundaries. It does imply participation in an activity system about which participants share understandings concerning what they are doing and what that means in their lives and in their communities (Lave and Wenger, 1991, p.98).

Embedded groups are integrative forces, pulling together a wide variety of resources across existing boundaries. The groups may be in the same or different locations, they may exist for long or short periods, and they may be more or less visible.

However, the lack of visibility also creates dangers. Invisible work is often less valued. The informality strengthens the flexibility of the embedded groups, but the flexibility may be undermined by attempts to formalize with rules and procedures. The ability to react 
adequately and quickly to a variety of more or less predictable situations requires some freedom of action.

Compared with most of the communities-of-practice described by Lave and Wenger (ibid), the embedded groups in this study differ in some respects. They are more heterogeneous regarding the types of work they perform, they may be more short-lived, and they include a larger variation of organizational positions and geographical locations.

The formal organization structure in Lake City features three groups - the transmission technicians, the operation control personnel and the network allocators. Overlaid on this formal structure, and stretching out into other parts of Telenor, are multiple overlapping embedded groups, more or less stable, which emerge and disappear with different activities, time and space.

One example is that of the ad hoc groups, for instance the informal task forces established on the fly to deal with malfunctions in the network. Such task forces are usually geographically distributed, cross formal organizational boundaries and are composed of persons from different job categories.

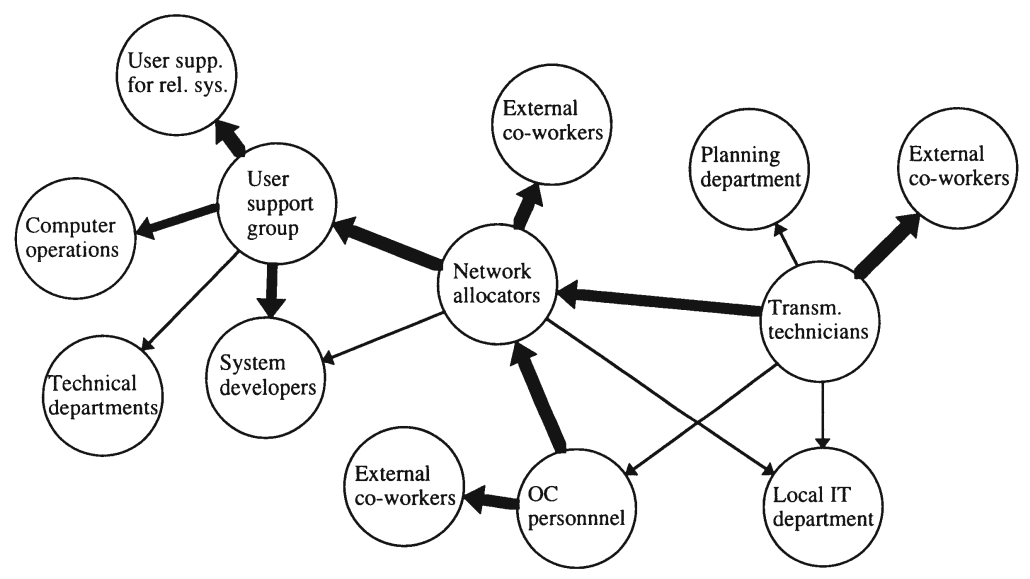

Figure 2 Network of informal NetSys related communication in Lake City and the usersupport group. Arrows indicate who asks whom, arrow widths indicate frequency. Each circle denotes an organizational unit, 'external co-workers' is a collective term for persons in units not otherwise specified.

There are also more stable groups, although membership may vary. One example is the network of NetSys users (see Figure 2). The group is not visible on any organizational chart, but everyone knows who its members are, who the experts are within the network, and which experts can be asked. The group is distributed geographically, as well as over a number of organizational units and types of work. Each circle denotes a separate 
organizational unit, and the widespread distribution of the network illustrates one of the problems outlined in section 2.1 on 'Grounding organizational learning'. What kind of organizational entity is actually the learning unit in this case ?

The graph illustrates the answers to the question "who do you ask when you have problems with NetSys ?", which explains the directedness of the graph. A more complete graph should also encompass the answers to the question "who asks you about NetSys problems?".

It is worth noting that this is not a 'flat' network in the sense that the nodes are person independent. There are personal relations involved, depending on who one knows, trust and like. There are types and degrees of expertness (see section below on 'Expert users'). Figure 2 should therefore be interpreted as two embedded groups: one constituted by the community of all NetSys users, and the other, not visible in the graph, the core of more expert NetSys users. The boundary between these two groups is not stable, however. It undulates according to accessibility (the experts may not be available), growing experience and job changes.

Another example of a relatively stable embedded group is the arrangement found in the transmission department. The technical assistant is formally employed in the Operation Control group, but works for the transmission technicians. She is 'borrowed' by the transmissions technicians, and even does some work for the regional operation center's top management.

\section{Texture and organizational learning}

The above discussion on links and embedded groups is a first attempt to clarify some of the textural aspects of an organization. The fluidity and elusiveness that 'organization' brings with it is due to the fact that the organization performing the work is both different from the formal organization as well as dynamic. The embedded groups are resources for information exchange and learning. The links described in the previous section are preconditions for these groups.

A textural approach to analyze organizational learning requires a change in focus from the formal structures to the actual structures that unfold when work is carried out. In the case of the regional operation center in Lake City, the organization in question is fluid, and constituted at any given time by the dynamic interaction pattern between persons with respect to their work. Analyses of acting or learning must take this into account, by specifying actors/learners and the particulars of the fluidity, like who interacts with whom, for what purpose, at what time and in what way.

\section{RESOURCES AND STRATEGIES FOR LEARNING}

Networkers have access to different types of learning resources. Some of these are pedagogical efforts concentrating on NetSys. These are central or local training courses held by the user-support group or by local experts. Others are learning resources integrated in the daily work in Lake City. These may be personal resources, such as individual systems 
of yellow stickers, notebooks, kardexes etc. They may also be socially structured resources, accessible for larger groups. Below some of these resources are outlined

\subsection{Overlapping competence}

A well known approach to developing a broadly competent workforce is to encourage overlapping competence. Semi-autonomous groups, as advocated in socio-technical theory and practice, is one way of dealing with this challenge. The rationale for developing overlapping competence may differ depending on the context. Bermann and Thoresen (1992) in a study of hotel work, found that overlapping competence were encouraged because of the central value associated with the welfare of the guests. They should not encounter the 'sorry,-but-you-must-ask-somebody-else'-attitude.

Different approaches to develop overlapping competence may be part of a conscious learning strategy, or it may be a result of accidental circumstances. Below some ways of developing overlapping competence amongst the networkers are described, together with the rationales behind each.

\section{Approaches to overlapping}

The OC staff views overlapping competences as an explicit ambition. To operate the OC desk one must deal with events in all telecommunications field. The weekend shifts in the $\mathrm{OC}$ room require OC personnel to work alone, necessitating a broad background to deal with all sorts of events.

To fulfill these requirements, it was an explicit policy to recruit specialist personnel, each with her own specialty like transmission, switching, installation etc. This would cover the range of qualifications necessary to run the operation control center as a whole. The turntaking at the OC desk is one way of developing overlapping competence.

The transmission technicians were in a somewhat different situation. Previously they were all-rounders, mastering different types of technologies. During the last 5-10 years the degree of specialization had increased, due to technological and organizational changes. Equipment changes faster than previously: new varieties appear several times a year while some old equipment could last several decades. The equipment is also more complicated, and more time is required to understand and operate it.

The technicians have a system of semi-overlap: each is responsible for knowing a technological field neigbouring upon their own specialty. 'The boundaries between jobs are jelly-like', one of the technicians remarked. In this way they can substitute for each other and to some extent reduce the vulnerability inherent in specialization. 'But the dream is to go all-round again' was also stated. The semi-overlap approach gives rise to another variety of embedded groups: those with similar technological knowledge and skills.

\subsection{Contexts that hamper learning}

The conditions for learning were not favourable at the time of my field work. The operation control group had recently been established and the new arrangements, within the regional operation center and between the center and the subordinate areas, were not always in place. This required a considerable amount of articulation work (Strauss, 1993, Gasser, 1986), and the management of real-time contingencies (Star, 1991) in particular. 
Most of the OC workers were new in their jobs and worked hard to manage the new situation. Not all positions had yet been filled, so there was some undermanning. Furthermore, the Olympic Games were two months away, which brought an extraordinary work load. The OC workers' strategy for coping with the situation was to lower the priority of activities not absolutely necessary for getting the job done. Learning more of NetSys was one of the activities that could be set aside for the time being. This worked because some expert users were physically close by and could be relied upon for trouble-shooting.

For the transmission technicians, the most obvious obstacle for learning NetSys was the fact that transmission technicians spend little time in their offices where the NetSys terminals are located. NetSys is a highly complex system to learn, which adds to the problems encountered by the technicians. Their strategy was to some extent hedging, i.e. avoiding use whenever possible, leading to a specialization wherein the technical assistant does most of the NetSys work. The relationship between the design of NetSys and its characteristics of use is further analyzed in Thoresen (1995).

However, the degree of hedging varies between regions and between areas within regions, and over time. Not all transmission technicians have a technical assistant, so they are forced to learn NetSys themselves. Furthermore, the position of assistant is gradually being eliminated as part of the reorganizing and down-sizing, and more transmission technicians will have to make do on their own.

In general, there are many ways in which establishing links may be restrained or discouraged. Work overload often leads to voluntary specialization. To get the job done, everyone does what $\mathrm{s} / \mathrm{he}$ is best at and can do most effectively. This tends to reduce the number of links. Management may enforce formal structures, e.g. by insisting on following the 'proper' information channels instead of shortcutting them. Thus the learning environment may be impoverished, and the flexibility of the work organization decreases. This is well known from working-by-the-rules strategies.

Pressure for efficiency further increases the workload and reduces the opportunities for maintaining and developing broad competence within the workforce.

\subsection{Job trajectories}

The concept of job trajectory is useful to understand how overlapping competence is developed through a mixture of planned and accidental circumstances. Strauss (1993) specifies 'trajectory' as follows:

(1) the course of any experienced phenomenon as it evolves over time and

(2) the actions and interactions contributing to its evolution (p.53-54).

The networkers job trajectories are constituted by the succession of jobs and organizational positions they have occupied during their career, and the corresponding skills and knowledge they have acquired. 'Positions' also include participating in e.g. projects, and union work, which is fairly common in Telenor.

Telenor has until recently been considered a company where one could spend one's entire work-life. Its size, variety of job categories, job security, in-house educational opportunities and country-wide location made it a desirable workplace. The average em- 
ployment time in my sample was more than twenty years, varying between 6 and 40 years. During this period, all the networkers had changed jobs and work places several times, sometimes voluntarily and sometimes enforced, due to reorganizations, downsizing and technological changes.

A characteristic of the networkers' job trajectories was that most job changes were related to the network in some way or another. The women started out with an education as telephone operators. Three of them (the fourth shifted to a technical education) then moved or were moved in many steps, and interrupted by in-house administrative courses, into their present jobs. Some of the men also started as telephone operators, but later entered the in-house courses for technical personnel: as installation workers, engineers, transmission technicians and sometimes lower-level management in the network field. These job categories in turn cover a variety of types of work. It is reasonable to believe that their competence extends well beyond their present job.

\subsection{Expert users}

The expert users are not a homogenous group. There are local and central expert users, and they vary according to type and scope of knowledge, accessibility, primary work and how they view their expertise. Different types of knowledge may be related to the physical network, or the database and its navigation. The scope of their expertise with NetSys may range from only a few specialties to NetSys in its entirety. Instead of expert users, it would be more appropriate to speak about types and degrees of 'expertness'.

A striking phenomenon with respect to one type of expertness is the need for knowing the whereabouts of Telenor employees, particularly those in the region. This means both the organizational location and the precise physical location at the time they are needed.

One example of this phenomenon concerns the need for rapid establishment of embedded groups for dealing with network failures. Establishment is carried out in relay chains - perhaps originating in the operation center, yet soon taken over by networkers in other parts of the region who report back and forth. Due to a number of recent reorganizations where people have been shuffled around, keeping track of who is where becomes a major concern. One type of expertise is to be able to quickly locate the right person. This task is facilitated by the information resources embedded in the varied job trajectories; the 'old hands' usually know someone in many Telenor workplaces. The 'old girls network' is particularly useful, since many are employed in Information Service, where locating people is their primary work.

The main local experts are the network allocators. They form the core of an embedded group in Lake City, with associated circles of more or less stable membership. They are in daily contact with the decentralized network allocators in other areas of the region, redistributing orders among themselves to adjust their work load, substituting for one another handling telephone calls etc.

Their expert position is based on the existing division of work, where network allocation and use of NetSys is specialized. They have also appropriated other resources for learning by dominating Users' Forum, the official participatory body for further development of NetSys. Their participation in Users' Forum provides close informational 
and influential contacts with the user-support group, and a country-wide social network among themselves which is influential due to their expert position.

The central experts are located in the user-support group. They have two main responsibilities: providing information and guidance, including courses, to all NetSys users, and heading further development of NetSys, in cooperation with the Users' Forum and two groups of in-house system developers. They are accessible to all NetSys users, and know a large number of them from teaching the internal courses. In Lake City, it is mostly the network allocators who contact them. The user-support group manager is a woman with background from the old manual network archives. She has participated from the very beginning of NetSys - in design and development of the system, the usersupport arrangements and the courses.

\subsection{Meeting-places}

The existence of meeting-places to exchange information and pick up useful news is essential to learning at work. Meeting-places may be related to activities, like regular meetings or shift changes, and they may be related to physical environments promoting communication and learning, like coffee rooms. They may be planned as meeting-places or not, - the point is that they function as opportunities for learning, and that they are cultivated as such.

Co-location is generally an important prerequisite for learning at work. The location of the network allocators in close proximity to the OC room makes communication easy. Figure 1 shows that the OC personnel primarily used the closest experts, who were the network allocators - 'Transmission is 20 meters away' as one OC worker remarked.

The physical environment of both the OC room and the transmission technicians' room are open landscapes. A landscape constitutes an informal meetingplace, with some advantages seen from a learning point of view (although they may be disadvantageous from a work environment point of view). It is easy to find somebody to ask, and the surrounding talk is a source of information. The technical assistant and the transmission technicians exploit this in their office landscape. The morning session in particular, when the print-outs of orders are distributed, functions as a meetingplace to inform the technical assistant and her co-workers about who will work where, who should not be disturbed, etc.

A particular form of communication in landscapes is out-in-the-air-questions. These are questions that are thrown out in no particular direction, and rely on somebody being able to answer. This form of communication is viewed as a sign of good working relations: 'Nobody says that you're asking too much, you always get an answer.' Similar communication practices are reported by Jordan (1992) and Heath and Luff (1991), although with a stronger emphasis on mutual updating. Jordan (ibid.) suggests that 'outlouds' work in workplaces where information resources are non-hierarchically distributed, a characteristic often associated with a good work environment.

More formal meeting-places are, for instance, group meetings, Users' Forum meetings and training courses. The training courses play an important role for a variety of reasons. They contribute to the establishment of personal relations between the user-support personnel and the NetSys users, as well as among the NetSys users. Personal relations fa- 
cilitate links and are conditions for the various informal networks to thrive. The courses also serve the purpose of confirmation - people realize that their experiences are similar, or dissimilar, to others'. The courses function as an arena for exchange of ideas of new or better ways of doing things. One aspect of the instructors' contribution is particularly interesting, since they frequently are links in learning chains - when information is transferred from one workplace to another through intermediaries. The user-support personnel's broad contact with the networkers provides them with information about problems and solutions all over the country, which they forward to those attending the courses.

It should be noted that training courses are valued among the networkers*. This is different from Orr's (1992) service technicians who found the courses too limited for their purpose. Part of the reason seems to be the differences in grounding the courses in practice. The NetSys instructors take care to anchor the teaching, excercises, and examples in practice. Development of new courses takes place in cooperation with the target groups. The user-support group manager's background from archiving, not from IT, is important to ensure this grounding. There is also a general awareness among the usersupport personnel of the situatedness and contingencies of daily practice, in contrast to canonical practice.

\section{SUMMARY}

Learning at work for the networkers in Lake City is facilitated by legitimate peripheral participation in practice, implying physical nearness to each other, use of telephone to easily reach remote coworkers, access to expert users, meeting-places, workplaces that allow peripheral awareness and out-in-the-air questions.

It is hindered by restraints on legitimate peripheral participation brought about by work pressure, division of work, enforced organizational boundaries, physical characteristics of the workplace, complexity of NetSys and varying degrees of usefulness of NetSys for different groups.

The networkers' learning of NetSys is smoothly embedded in their practical work: actions and interactions within communities-of-practice aimed at keeping the network in good shape. This is not to say that there are no hindrances. The point is that when opportunities for learning arise within the context of daily practice, they are also exploited by the networkers. Thus, learning at work is also learning through work.

The cognitive view of organizational learning tends to delete or abstract the work carried out. One of the dangers of this non-visibility is that the concrete actions and the concrete resources needed to successfully appropriate IT disappear in general formulations.

\footnotetext{
* This is true mostly for those attending the more recent courses. The early courses were not well received.
} 


\section{ACKNOWLEDGEMENTS}

Thanks to Arve Meisingset and Birgit Andvin for their critique, comments and helpfulness in elucidating NetSys' trajectory and commenting on the paper. Thanks also to Susan Leigh Star, Lucy Suchman, Ina Wagner, Mike Hales, Julian Orr, Frieder Nake and Peter Holmes for encouragement, for help in clarifying topics and presentation, and for literature guidance. The anonymous reviewers provided many helpful comments. Thanks also to the networkers in Lake City and the user-support group for their patience and willingness to share their working knowledge with me.

The work was supported by Grant No. 100684/410 from the Norwegian Research Foundation and the Norwegian Computing Center.

\section{REFERENCES}

Bermann, T. and Thoresen, K. (1992). Konferansesenteret. In Thoresen, K. and Keul, V. (Eds.), Omstilling med IT, NKS-Forlaget, Oslo, 99-116 (Norwegian only)

Clement, A., Kolm, P. and Wagner, I. (1994). NetWORKing: Connecting Workers In and Between Organizations. IFIP Trans.A-38, North-Holland, Amsterdam, 1-250.

Cook, S.D.N. and Yanow, D. (1993). Culture and Organizational Learning. Management Inquiry, Vol.2, No.3.

Damanpour, F. (1991). Organizational Innovation: A Meta-Analysis of Effects of Determinants and Moderators. Acad. of Management Journal, Vol.34, No.3, 555-90.

Dodgson, M. (1993). Organizational Learning: A Review of Some Literatures. Organization Studies, 14/3, 375-94.

Dorroh, J.R., Gulledge, T.R. and Womer, N.K. (1994). Investment in Knowledge: A Generalization of Learning By Experience. Management Science, Vol.40, No.8, 947-58.

Duimering, P.R., Safayeni, F. and Purdy, L. (1993). Integrated Manufacturing: Redesign the Organization Before Implementing Flexible Technology. Sloan Management Review, Vol.34, No.4, 47-56.

Fiol, C.M. and Lyles, M.A. (1985). Organizational Learning. Acad. of Management Review, Vol.10, No.4, 803-13.

Franke, R.H. (1987). Technological Revolution and Productivity Decline: Computer Introduction in the Financial Industry. Technological Forecasting and Social Change, 1, 143-54.

Gasser, L. (1986). The Integration of Computing and Routine Work. ACM Trans. on Office Information Systems, Vol.4, No.3, 205-25

Gerson, E.M. and Star, S.L. (1986). Analyzing Due Process in the Workplace. ACM Trans. on Office Information Systems, Vol.4, No.3, 257-70.

Hammer, M. (1990). Reengineering Work: Don't Automate, Obliterate. Harvard Business Review, July-August 1990, 104-12.

Heath, C. and Luff, P. (1992). Collaboration and Control. Crisis Management and Multimedia Technology in London Underground Line Control Rooms. Computer Supported Cooperative Work, Vol.1, No.1-2, 69-94. 
Hedberg, B. (1981). How Organizations Learn and Unlearn. In Nystrom, P.C. and Starbuck, W.H. (Eds.), Handbook of Organizational Design, Vol.1,Oxford University Press, 3-27.

Herbig, P.A. and Kramer, H. (1993). Low Tech Innovation: Resurveying the Basic Meaning of Innovation. Management Decision, 31/3, 4-7.

Huber, G.P. (1991). Organizational Learning: The Contributing Processes and the Literatures. Organization Science, Vol.2, No.1, 88-115.

Iden, J. (1995). Workflow Management: What Does the Literature Say ? Report No.36, ISSN 0803-6489. Univ. of Bergen, Norway, Dept. of Information Science, 1-18.

Jones, M. (1994). Don't Emancipate, Exaggerate: Rhetoric, Reality and Reengineering. In Baskerville, R., Smithson, S., Ngwenyama, O. and De Gross, J.I(Eds.), Proceedings of IFIP Conference, 357-77.

Jordan, B. (1992). Technology and Social Interaction: Notes on the Achievement of Authoritative Knowledge in Complex Settings. IRL Report NO. IRL92-0027, 1-58.

Kanter, R.M. (1988). The Change Masters Unwin Paperbacks, London, UK, 1-432.

Keen, P.G.W., Bronsema, G. and Zuboff, S. (1982). Implementing Common Systems: One Organization's Experience. Systems, Objectives, Solutions, 2, 125-42.

Levitt, B. and March, J.G. (1988). Organizational Learning. Annual Review of Sociology, Vol.14, No.3, 319-40.

March, J.G. and Olsen, J.P. (1979). Ambiguity and Choice in Organizations. Universitetsforlaget, Oslo, Norway, 2.edition, 1-408.

March, J.G. (1991). Exploration and Exploitation in Organizational Learning. Organization Science, Vol.2, No.1, 71-87.

Meisingset, A. (1993). Human-machine interface design for large systems. Telektronikk, Vol.89, No.2/3, 11-20.

Orr, J. (1991). Contested Knowledge. Anthropology of Work Review, 12(3), 12-7.

Orr, J.E. (1992). Ethnography and Organizational Learning: In Pursuit of Learning at Work. NATO Advanced Research Workshop, 'Organizational Learning and Technological Change. Siena, Italy, September 22-26.

Pape, T. and Thoresen, K. (1987). Development of Common Systems by Prototyping. In Bjerknes, G., Ehn, P. and Kyng, M. (Eds.), Computers and Democracy, Avebury, UK, 297-311.

Pape, T. and Thoresen, K. (1990). Evolutionary prototyping in a change perspective. A tale of three municipalities. Information Technology \& People, 6:2-3, 145-70.

Rowe, C.J. (1985). Identifying causes of failure: a case study in computerized stock control. Behaviour and Information Technology, Vol.4, No.1, 63-72.

Sachs, P. (1994). Transforming Work: The Role of Learning in Organizational Change. HICSS-27 Monograph on Representations of Work, Ed. L.Suchman. Hawaii International Conference on System Sciences, 36-43

Simon, H.A. (1991). Bounded Rationality and Organizational Learning. Organization Science, Vol.2, No.1, 125-134.

Star, S.L. (1991). The Sociology of the Invisible: The Primacy of Work in the Writings of Anselm Strauss. In Maines, D. (Ed.), Social organization and Social Processes: Essays in Honour of Anselm Strauss. Hawthorne, NY, Aldine de Gruyter. 
Strauss, A., Fagerhaugh, S., Suczek, B. and Wiener, C. (1985) Social Organization of Medical Work. The University of Chicago Press, U.S., 1-310.

Strauss, A.L. (1993). Continual Permutations of Action. Aldine de Gruyter, NY, 1-280.

Suchman, L. (1983). Office Procedures as Practical Action: Models of Work and System Design. ACM Transactions on Office Information Systems, Vol.1, No.4, 320-8.

Suchman, L. (1987). Plans and Situated Actions. Cambridge University Press, U.S., 1-203.

Thoresen, K. (1995). Design for Heterogeneity. Proceedings of Computers in Context: Joining Forces in Design, Aarhus, Denmark, August 14-18, 1995, 60-72.

Van de Ven, A.H. and Rogers, E.M. (1988). Innovations and Organizations. Critical Perspectives. Communication Research, Vol.15, No.5, 632-51.

Wagner, I. (1994). Networking Actors and Organizations. Computer Supported Cooperative Work (CSCW), 2, 5-20.

Wardell, M. (1992). Changing Organizational Forms: From the Bottom Up. In Reed, M. and Hughes, M. (Eds.), Rethinking Organization. New Directions in Organization Theory and Analysis. Sage Publ., 144-64.

Weick, K.E. (1991). The Nontraditional Quality of Organizational Learning. Organization Science, Vol.2, No.1, 116-139.

Wynn, E. (1979). Office Conversation as an Information Medium. Ph.D. Thesis, Berkeley, Dept.of Anthropology.

\section{BIOGRAPHY}

Majored in geology in 1966 at the University of Oslo, assistant professor at the Mineralogical-Geological Museum in Oslo. Research scientist at the Norwegian Computing Center since 1972. Professional interests: change processes, participatory design, and work environment issues related to information technology in organizations. Research approaches include both action oriented and analytic studies in post offices, town and country planning departments, hospitals, hotels, and telecommunication companies. 